\title{
A Quantitative Disease Severity Rating Scale for Northern Corn Leaf Blight
}

\begin{abstract}
Trey Price, Myra Purvis, and Hunter Pruitt, Macon Ridge Research Station, Louisiana State University Agricultural Center, Winnsboro
\end{abstract} 71295

Accepted for publication 15 March 2016. Published 28 March 2016.

Price, T., Purvis, M., and Pruitt, H. 2016. A quantitative disease severity rating scale for northern corn leaf blight. Plant Health Prog. 17:49-50.

Northern corn leaf blight (NCLB), caused by Exserohilum turcicum (Pass.) K. J. Leonard and E. G. Suggs, is a fungal disease that is an annual issue in corn-producing areas in the United States. Losses due to NCLB are variable, but severe epidemics may result in up to $50 \%$ yield loss if the disease is established prior to silking (White et al. 2010). The disease also can be particularly severe when infection occurs early (prior to tasseling) and conditions are optimal for disease development (18 to $27^{\circ} \mathrm{C}$ with prolonged periods of moisture) (White et al. 2010). Most producers apply fungicides to corn infected with NCLB to slow disease development and preserve yield potential. Researchers throughout the United States conduct fungicide efficacy trials annually, and NCLB is usually visually estimated as a percentage by the rating scientist (e.g., Roberston and Shriver 2014). A diagrammatic scale was recently developed in Brazil utilizing image analysis software to estimate percentages (Vieira et al. 2014). Perceptions of disease severity may be variable among disease rating technicians; therefore, the objective of this project was to create a non-biased tool that can be used to increase the accuracy of NCLB ratings.

To obtain images of NCLB, infected leaves of multiple hybrids located at the ear or above were obtained on three dates from midJune to early July 2015 in three locations in northeast Louisiana. Leaves were immediately placed in coolers at approximately $4^{\circ} \mathrm{C}$. In the laboratory, leaves were flattened between cardboard under a $4.5 \mathrm{~kg}$ weight for $1 \mathrm{~h}$ prior to placing on black cloth, which was used as a background. Images were obtained with a 3.2 megapixel Olympus C-760 UltraZoom digital camera set on "auto"

(Olympus America Inc., Center Valley, PA) mounted to a tri-pod at $0.5 \mathrm{~m}$ above the leaves.

Assess 2.0 (American Phytopathological Society, St. Paul, $\mathrm{MN}$ ), an image analysis software for plant disease quantification, was used to analyze photographs. The automatic analysis panel was used, and "\% Area" was initially selected to define lesion margins. The "Leaf/Lesion" toggle was used to confirm that the leaf was defined as the area of interest (AOI), and that the lesion areas were properly defined. If adjustments were needed, the manual analysis panel was utilized with color planes adjusted to refine AOI and/or lesion area. The percentage of lesion area was recorded as disease severity, and a rating scale was constructed using representative images for each scale increment (Fig. 1).

Corresponding author: Trey Price. Email: pprice@agcenter.lsu.edu.

doi:10.1094/PHP-RS-16-0010

(C) 2016 The American Phytopathological Society

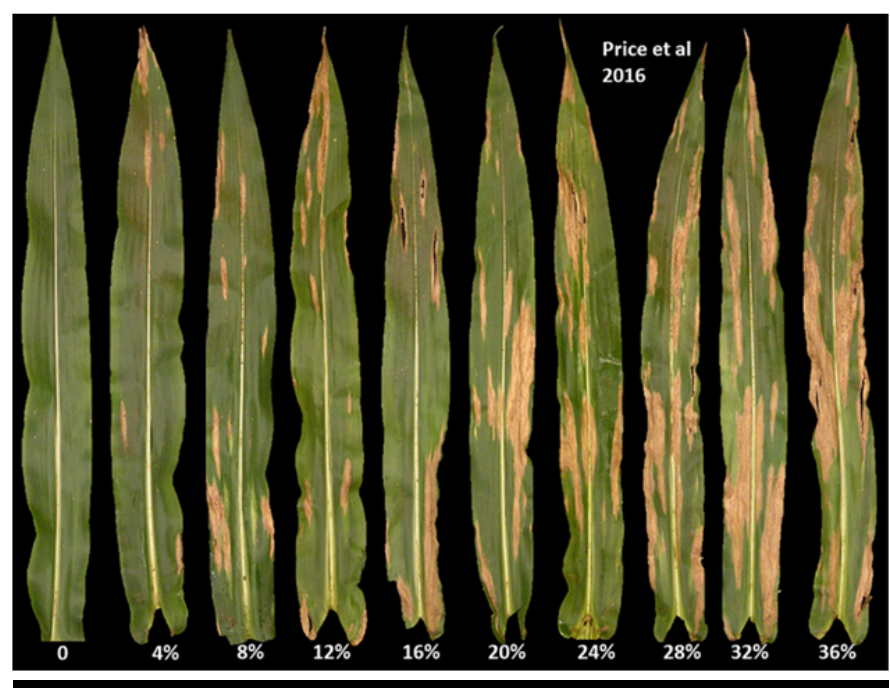

FIGURE 1

Northern corn leaf blight rating scale.

The image analysis program usually efficiently defined NCLB lesions. In situations where leaves were not completely flat, there were problems with defining the AOI, and these images were discarded. Efficiently defining lesion area was problematic in leaves with significant discoloration or tearing due to other factors such as: herbicide damage, nutrient deficiency, or wind damage, and these images also were discarded. Leaves that were dark green in color, with no other damage other than NCLB lesions, were ideal for estimating disease severity.

Although the range of this scale is limited, refined versions that cover a broader range of disease severity may be constructed using these methods. A disadvantage of this scale is that users may only assess one leaf at a time, which requires sampling of many leaves to accurately define overall disease severity.

Nonetheless, this scale may be used to estimate disease severity in producer fields, which may aid in NCLB management decisions. There are additional potential applications in research such as estimating NCLB severity in hybrid screenings and foliar fungicide efficacy trials. Since this scale is quantitative, it can be used instead of or in conjunction with qualitative scales, thereby increasing accuracy and statistical validity of results. Potentially, this type of disease severity analysis could be used in developing action thresholds for NCLB in the future. 


\section{LITERATURE CITED}

Robertson, A., and Shriver, J. 2015. Evaluation of fungicide application timing on northern corn leaf blight and yield in field corn, 2014. Plant Dis. Manag. Rep. 9:FC056. doi:10.1094/PDMR09.
Vieira, R. A., Mesquini, R. M., Silva, C. N., Hata, F. T., Tessman, D. J., and Scapim, C. A. 2014. A new diagrammatic scale for the assessment of northern corn leaf blight. Crop Protect. 56:55-57.

White, D. G. 2010. Compendium of Corn Diseases, 3rd ed. American Phytopathological Society, St. Paul, MN. 